Table Vasculitic organ involvement and immunological features in patients with primary or secondary RP

\begin{tabular}{llllll}
\hline Patient & Organ involvement & cANCA & pANCA & Coll II Ab & Disease \\
\hline 1 & - & & + & RP \\
2 & B, (K), N, E, Ey, H, S & + & & WG + Rp \\
3 & B, E, (K) & + & & WG + RP \\
4 & B, (K), N, Ey, H, S & & + & mPA + RP \\
5 & B, E, (K) & & + & mPA + RP \\
6 & B, N, Ey & & + & mPA + RP \\
7 & B, N, H & & & cPAN + RP
\end{tabular}

Extended ELK-Classification (Nölle et al 1989): B = constitutional symptoms, E = ENT, Ey = eye, $\mathrm{H}=$ heart, $(\mathrm{K})=$ kidney (non dialysis dependant), $\mathrm{S}=$ skin, $\mathrm{N}=$ nervous system, WG = Wegener's granulomatosis, $\mathrm{mPA}=$ microscopic polyangitis, $\mathrm{cPAN}=$ classic panarteritis nodosa, $\mathrm{RP}=$ relapsing polychondritis

1 Papo T, Piette J C, Le Thi Huong Du et al. Antineutrophil cytoplasmic antibodies in polychondritis. Ann Rheum Dis 1993; 52: 384-5.

2 Nölle B, Specks U, Lüdemann J, Rohrbach $M$ S, DeRemee R A, Gross W L. Anticytoplasmic Autoantibodies: Their Granulomatosis. Ann Interm Med 1989; 111: 28-40.

3 Cohen Tervaert J W, Huitema M G, Hene R J, et al. Prevention of relapses in Wegener' et al. Prevention of relapses in Wegener's granulomatosis by treatment based on antineutrophil cytoplas

4 Handrock K, Schwarz-Eywill M, Kekow J, Gross W L. Rezidivierende Polychondritis: Eine eigene Entität oder Symptom eine systemischen -Vaskulitis? Medizinische Klinik 1993; 88(2): 3 .

5 McAdam L P, O'Hanlan M A, Bluestone R, Pearson C M. Relapsing polychondritis: Prospective study of 23 patients and a review of the literature. Medicine 1976; 55: 193

6 Jennette J C, Falk R J, Andrassy K, et al. Nomenclature of systemic vasculitides: the proposal of an international consensus conference. Arthr Rheum 1993 (in press).

7 Leavitt R Y, Fauci A S, Bloch D A, et al. The American College of Rheumatology 1990 American College of Rheumatology 1990
criteria for the classification of Wegener's criteria for the classification of Wegener's
granulomatosis. Arthr Rheum 1990; 33(8): granulomat

8 Herman $\mathrm{H}$ J, Dennis $M$ V. Immunopathologic studies in relapsing polychondritis. $\mathcal{F}$ Clin Invest 1973; 52: 549-58.

9 Small P, Black M, Davidman M, Brisson de Champlain M L, Kapusta M A, Kreisman H Wegener's granulomatosis and relapsing polychondritis: a case report. $f$ Rheumatol 1980; 7: 915-8

10 Michet C J, McKenna C H, Luthra H S, O'Fallon W M. Relapsing Polychondritis manifestations. Ann Int Med 1986; 104: manif

11 Chang-Miller A, Okamura M, Torres V, et al. Renal Involvement in Relapsin Polychondritis. Medicine 1987; 66: 202-17.

AUTHORS' REPLY: In their series of seven patients with relapsing polychondritis (RP), Handrock and Gross could detect ANCA in six patients, two with Wegener's granulomatosis (WG), three with microscopic polyangiitis and one with classical polyarteritis nodosa. They conclude that the presence of ANCA in RP indicates that polychondritis occurs as a secondary event of a primary systemic vasculitis.

Our experience is very different. Among our eight ANCA-positive RP patients, three only had vasculitis. ${ }^{1}$ Among these three, WG could be diagnosed in only one with low titre $(1 / 20)$ P-ANCA. The two others, one with C-ANCA and one with P-ANCA, had minor cutaneous vasculitis and no visceral involvement. Among our 25 ANCA-negative patients, nine had vasculitis (cutaneous in seven, quiescent WG in one, mononeuritis multiplex in one). These data indicate that ANCA may be detected in RP without defined systemic vasculitis, including microscopic polyangiitis. In the Mayo Clinic experience, eight of 22 patients with RP had ANCA with perinuclear or nuclear pattern. Such discrepancies might result from recruit- ment bias and/or differences in the size of the studied groups, but also from the majo problem of diagnostic procedures which requires further discussion.

Obviously, vascular involvement is frequent in RP and can affect vessels of any size, from aorta to capillaries. Its frequency has been said to be as high as $56 \%$ in McAdam's series. ${ }^{3}$ In RP, microscopic angiitis has proved to represent the anatomical basis responsible for dermatological and renal manifestations, and is suspected to cause neuropathies, audiovestibular disturbances and episcleritis. ${ }^{34}$

$\mathrm{RP}$ is frequently associated with various inflammatory or autoimmune disorders, ranging from ulcerative colitis and rheumatoid arthritis, two ANCA-associated diseases, ${ }^{56}$ to thyroiditis, spondylarthropathies and primary systemic vasculitides, including Behcet's syndrome. ${ }^{7-9}$ Some of these diseases are clearly distinct from RP but associated with, while others share, many manifestations with RP which results in obscure nosological considerations and difficult differential diagnosis. The main problem is trying to distinguish $\mathrm{RP}$ from $\mathrm{WG},{ }^{10}$ since both diseases frequently have striking similarities, mainly saddle nose deformity and laryngotracheal involvement (although resulting from different processes), arthritis, episcleritis and skin vasculitis. Necrotising glomerulonephritis, otitis, sinusitis, nasal septal perforation and proptosis, which are more suggestive of WG, also occur in a smal percentage of patients with $\mathrm{RP}^{8}{ }^{10}$ Unfortunately, tests for ANCA are not available in reports for those patients with 'atypical' manifestations of RP. Last but no least, auricular chondritis, which is supposed to be the hallmark of RP, has been described in a few patients with WG. ${ }^{11} 12$ Facing this critical problem, physicians can get help from histological data and from some more specific clinical manifestations such as lung cavitary infiltrates or peculiar dermatological involvement for WG, ${ }^{13}$ and conversely for RP diffuse tracheobroncheal dynamic collapse, ascending aorta aneurysm or dysmyeolopoietic syndrome in the absence of previous immunosuppressive treatment. ${ }^{414}$ These features may diagnose some intriguing patients as probably having auricular chondritis in the course of an otherwise unremarkable WG. ${ }^{11}{ }^{12}$ In the absence of clearly discriminating data, an overlap between RP and WG is the only conclusion, as described in a case we recently reported. ${ }^{15}$ Such puzzling problems, however, experience of $100 \mathrm{RP}$ and 75 WG. Extending the question to the whole spectrum of systemic vasculitis encountered in $R P$ increases the ratio of patients concerned to 11 of 112 in Michet's series, ${ }^{7}$ which remains far less frequent than suggested by Handrock and Gross. are restricted to less than $5 \%$ of cases in our
Nevertheless, we agree with these authors that chondritis can probably occur as an epiphenomenon in the course of some definite inflammatory disorders. This is true not only for primary systemic vasculitides, but also for systemic lupus erythematosus, ${ }^{10}$ possibly for other rheumatic diseases, and even for lepromatous leprosy. ${ }^{17}$ Under such circumstances, cartilage involvement frequently differs from the typical features of $\mathrm{RP}$, regarding the usual sparing of the respiratory tree and the lack of a relapsing/ remitting course which defines RP. Histological data on auricular chondritis is rare.

A clear-cut categorisation of patients with vasculitic manifestations and chondritis seems impossible. Definitions of RP, WG and other vasculitides are inherited and remain purely descriptive of clinical symptoms and pathological data that sometimes overlap, in the absence of a comprehensive view of their pathophysiology and aetiology. Recent studies on ANCA have provided new and promising insights into the processes involved, but their application to diagnosis is mainly restricted to the close association of WG with ANCA specific for proteinase 3 , which were constantly negative in our patients with RP. ${ }^{1}$ Computer-derived criteria for the classification of vasculitides, such as those developed by the American College of Rheumatology are important for large studies but not particularly relevant for individual patients, especially in the discussion of overlaps between diseases sharing many manifestations. For example, a patient with a typical history of RP complicated by renal involvement switches to the diagnosis of WG in case of epistaxis, ${ }^{18}$ a symptom only occurring occasionally in RP. ${ }^{3}$ Conversely, a patient with a history of WG, including arthritis and episcleritis, can be classified as RP if auricular chondritis occurs, according to the empirical criteria used by Michet.

Finally, some practical conclusions can be drawn for clinicians. In most cases RP is a primary disease, even in the presence of vascular manifestations. It should not be considered or treated as a vasculitis on the sole basis of ANCA positivity. However, in some rare cases patients share manifestations of RP and WG. Due to the poor response of WG to steroids alone, first-line regimes used in such patients with RP/WG overlap should probably include additional cyclophosphamide. $^{15}$

J C PIETTE T PAPO LE THI HUONG DU Service de Médecine Interme, Groupe Hospitalier Pitié-Salpêtrière, 75651 Paris Cedex 13,

France

O MEYER

Service de Rhumatologie Hopital Bichat, 18 Paris,

1 Papo T, Piette J C, Le Thi Huong Du, et al. Antineutrophil cytoplasmic antibodies in polychondritis. Ann Rheum Dis 1993; 52: 384-5.

2 Specks U, Wheatley C L, McDonald T J, Rohrbach M S, De Remee R A. Anticytoplasmic autoantibodies in the diagnosis and follow-up of Wegener's granulomatosis. Mayo Clin Proc 1989; 64: 28-36.

3 McAdam L P. O'Hanlan M A, Bluestone R, Pearson C M. Relapsing polychondritis. Prospective study of 23 patients and a review of the literature. Medicine 1976; 55: 193-215.

4 Michet C J. Vasculitis and relapsing polychondritis. Rheum Dis Clin North Am 1990; 16: $441-4$. 
5 Halbwachs-Mecarelli L, Nusbaum P, Noel L H et al. Antineutrophil cytoplasmic antibodie (ANCA) directed against cathepsin G in ulcerative colitis, Crohn's disease and primary sclerosing cholangitis. Clin Exp Immunol 1992; 90: 79-84

6 Mulder A H L, Horst G, Van Leeuwen M A Limburg P C, Kallenberg C G M. Antineutrophil cytoplasmic antibodies in rheumatoid arthritis. Characterisation and clinical correlations. Arthritis Rheum 1993; 36: 1054-60.

7 Michet C J Jr, McKenna C H, Luthra H S, O'Fallon W $M$. Relapsing polychondritis. Survival and predictive role of early disease Survival and predictive role of early disease
manifestations. Ann Intern Med 1986; 104: manifest

8 Vinceneux $\mathrm{Ph}$, Pouchot J, Piette J C Polychondrite atrophiante. In: Kahn $M$ F Peltier A P, Meyer O, Piette J C, eds. Les maladies systémiques Paris: Flammarion Médecine-Sciences, 1991: 735-50.

9 Ueno Y, Chia D, Barnett E V. Relapsing polychondritis associated with ulcerative colitis. Serial determinations of antibodies to cartilage and circulating immune complexes by three assays. $f$ Rheumatol 1981; 8: $456-61$.

10 Chang-Miller A, Okamura M, Torres V E, et al. Renal involvement in relapsing polyRenal involvement in relapsing p
chondritis. Medicine 1987; 66: 202-17.

11 Diaz-Jouanen E, Alarcon-Segovia D Chondritis of the ear in Wegener's granulomatosis. Arthritis Rheum 1977; 20: 1286-8.

12 Small P, Black M, Davidman M, Brisson De Champlain M L, Kapusta M A, Kreisman H. Wegener's granulomatosis and relapsing polychondritis: a case report. $\mathcal{f}$ Rheumatol 1980 7: 915-8.

13 Frances C, Le Thi Huong D U, Piette J C, et al. Wegener's granulomatosis: dermatological manifestations in 75 cases with clinicopathologic correlation. Arch Dermatol (in press).

14 Piette J C, Prince-Zucchelli M A, Herson S, et al. Relapsing polychondritis and chronic al. Relapsing polychondritis and chronic
refractory anemia. Arthritis Rheum 1985; 28: refractor

15 Cauhape $\mathrm{Ph}$, Aumaitre O, Papo Th, et al. A diagnostic dilemma: Wegener's granulomatosis, relapsing polychondritis or both? Eur $\mathcal{f}$ Med (in press)

16 Kitridou R C, Wittmann A L, Quismorio F P Jr. Chondritis in systemic lupus erythematosus: clinical and immuno5: 349-53

17 Piepkorn M, Brown C, Zone J. Auricular chondritis as a rheumatologic manifestation of Lucio's phenomenon: clinical improvement after plasmapheresis. Ann Intern Med 1983; 98: 49-51.

18 Leavitt R Y, Fauci A S, Bloch D A, et al. The American College of Rheumatology 1990 American College of Rheumatology 1990 criteria for the classification of Wegener's
granulomatosis. Arthritis Rheum 1990; 33: granulor $1101-7$.

\section{Can arterial \\ catheterisation induce autoimmune disease?}

Struthers et $a l^{1}$ reported a case of polyartheritis nodosa (PAN) related to angioplasty. However, the absence of cholesterol emboli on muscle biopsy material was not mentioned in that paper. This could be an interesting fact as patients with cholestero microembolisation, after arterial procedures, have been described as presenting features of PAN. ${ }^{2}$

We admitted a 66 year old man, who underwent cardiac catheterisation and presented with malaise, fever, livedo reticularis, purpura, distal ischaemic lesions in lower extremities with normal peripheral pulses, six weeks after the invasive procedure. On admission, he developed stupor, renal failure and mesenteric ischaemia, and died of multiorgan failure. The most remarkable laboratory findings were: elevated erythrocyte sedimentation rate, anaemia, mild leucocytosis with eosinophilia, thrombopenia increased nitrogen and creatinine, and positive circulating immune complexes, rheumatoid latex and antinuclear antibodies. Antineutrophil citoplasmatic antibodies, antiglomerular basement membrane antibodies, antiphospholipid antibodies and cryoglobulins were negative. Serum complement was normal. Blood cultures and hepatitis B antigens were negative. Muscle biopsy disclosed cholesterol microembolisation in the small vessels and inflammatory vascular infiltrate.

In this patient, histological findings were consistent with multiple embolisation cholesterol disease (MECD), but clinical and biological features strongly suggested autoimmune disease associated with vasculitis of the small and medium arteries. Although the precise pathogenesis of MECD remains uncertain, its close similarity to necrotising vasculitis point to an immunological phenomena probably triggered by mechanical or ischaemic endothelium damage during invasive procedures. Similar case reports ${ }^{1-3}$ could be involved in the wide clinical and biological spectrum of the same underlying disease.

R M CABRAL SUSANO L C MONTERO F A FIERRO

Department of Medicine

J F MOSQUERA

Division of Immunolog Hospital General de Asturias, University Centre, Oviedo, Spain

1 Struthers G R, Pough M T, Woodward D A Polyartheritis nodosa following angioplasty. Ann Rheum Dis 1993; 52: 247.

2 Cosserat J, Bletry O, Frances C, et al. Embolies multiples de cholestérol simulant une multiples de cholesterol simulant une 557-64.

3 Hillion D, Durst P, Baglin A, Franc B Caubarrere I, Fendler J P. Syndrom d'hémorragie alvéolaire associé à des embolies systemiques de cholésterol. Ann Med Interne 1986; 137: 660-2.

\section{LETTER TO THE EDITOR}

\section{Alcohol, androgens and arthritis}

As recently discussed by James, ${ }^{1}$ patients with rheumatoid arthritis (RA) frequently have depressed androgen synthesis. It is well established that alcohol, though it may increase libido, lowers men's testosterone concentrations. $^{2}$ Provided that depressed androgen synthesis in patients with RA is a predictor rather than a consequence of the disease, it might be expected that alcoho consumption would be a risk factor for RA.

To test this hypothesis, we studied alcohol consumption for its association with the incidence of seropositive RA in a cohort of Finnish men. In this cohort, the questionnaire measure for total alcohol intake proved to be reliable at an interval of half a year (intraclass correlation coefficient, $r=0.73$ ) and closely associated with the incidence of severe fall injuries. ${ }^{3} \mathrm{RA}$ cases were identifed on the basis of their entitlement to free medication under the sickness insurance covering the entire population of Finland. ${ }^{4}$ In the 9777 men who had neither arthritis nor a previous history of it at the start of the study, 30 incident cases of seropositive RA occurred during 134083 person years

In men consuming more than $500 \mathrm{~g}$ per month of alcohol (table), the age-adjusted relative risk of seropositive RA seemed to be slightly elevated (model 1 ). There are many factors, however, that correlate closely with alcohol use and could confound this association. Drinking and smoking, in particular, are related habits, and in this cohort smoking was a strong risk factor for seropositive RA in males. ${ }^{4}$ When allowance was made on potential confounders, the association between alcohol consumption and RA incidence even turned to inverse (model 2).

Thus our study does not provide any evidence for the role of alcohol as a risk factor for RA.

$\mathrm{KAHO}$

$M$ HELIOVAARA National Public Health Institute and the Social Insurance Institution, Helsinki, Finland

Correspondence to: Dr Aho, National Public Health Institute, Mannerheimintie 166, SF-00300 Helsinki, Finland.

1 James W H. Rheumatoid arthritis, the contraceptive pill, and androgens. Ann Rheum Dis 1993; 52: 470-4.

2 Bertello P, Gurioli L, Gatte G, Pinna G, Angel A. Short term ethanol ingestion can effect the testicular response to single dose human chorionic gonadotropin in normal subjects. $f$ Endocrinol Invest 1986; 9: 249-52.

3 Malmivaara A, Heliövaara $M$, Knekt $P$ Reunanen A, Aromaa A. Risk factors for Reunanen A, Aromaa A. Risk factors for adults. $A m$ f Epidemiol (in press)

4 Heliövaara M, Aho K, Aromaa A, Knekt P Reunanen A. Smoking and risk of rheumatoid arthritis. $\mathcal{F}$ Rheumatol (in press).

Table Alcohol intake and the risk of seropositive rheumatoid arthritis $(R A)$

\begin{tabular}{|c|c|c|c|c|c|c|}
\hline \multirow[b]{2}{*}{$\begin{array}{l}\text { Alcohol intake } \\
(\mathrm{g} / \text { month })\end{array}$} & \multirow[b]{2}{*}{$\begin{array}{l}\text { Number } \\
\text { of men } \\
\text { examined }\end{array}$} & \multirow[b]{2}{*}{$\begin{array}{l}\text { Number } \\
\text { of } R A \\
\text { cases }\end{array}$} & \multicolumn{2}{|l|}{ Model $1^{\star}$} & \multicolumn{2}{|c|}{ Model $2 \dagger^{\star}$} \\
\hline & & & $\begin{array}{l}\text { Relative } \\
\text { risk }\end{array}$ & $\begin{array}{l}95 \% \text { confidence } \\
\text { interval }\end{array}$ & $\begin{array}{l}\text { Relative } \\
\text { risk }\end{array}$ & $\begin{array}{l}95 \% \text { confidence } \\
\text { interval }\end{array}$ \\
\hline 0 & 2470 & 7 & $1 \cdot 0$ & & 1.0 & \\
\hline 1-99 & 1274 & 4 & $1 \cdot 1$ & $0.3-3 \cdot 6$ & 0.9 & $0 \cdot 3-3 \cdot 2$ \\
\hline $100-499$ & 3782 & 10 & 0.9 & $0 \cdot 3-2 \cdot 3$ & 0.6 & $0 \cdot 2-1 \cdot 6$ \\
\hline $500-$ & 2251 & 9 & $1 \cdot 3$ & $0.5-3.6$ & 0.8 & $0 \cdot 3-2 \cdot 2$ \\
\hline
\end{tabular}

^Cox's life-table regression adjusting for age.
†Adjusting for age, marital status, level of education, smoking, body mass index and physical activity at leisure. 